Supplement of Atmos. Chem. Phys., 16, 8125-8140, 2016

http://www.atmos-chem-phys.net/16/8125/2016/

doi:10.5194/acp-16-8125-2016-supplement

(C) Author(s) 2016. CC Attribution 3.0 License.

(c) (i)

Supplement of

\title{
The millennium water vapour drop in chemistry-climate model simulations
}

Sabine Brinkop et al.

Correspondence to: Sabine Brinkop (sabine.brinkop@dlr.de)

The copyright of individual parts of the supplement might differ from the CC-BY 3.0 licence. 

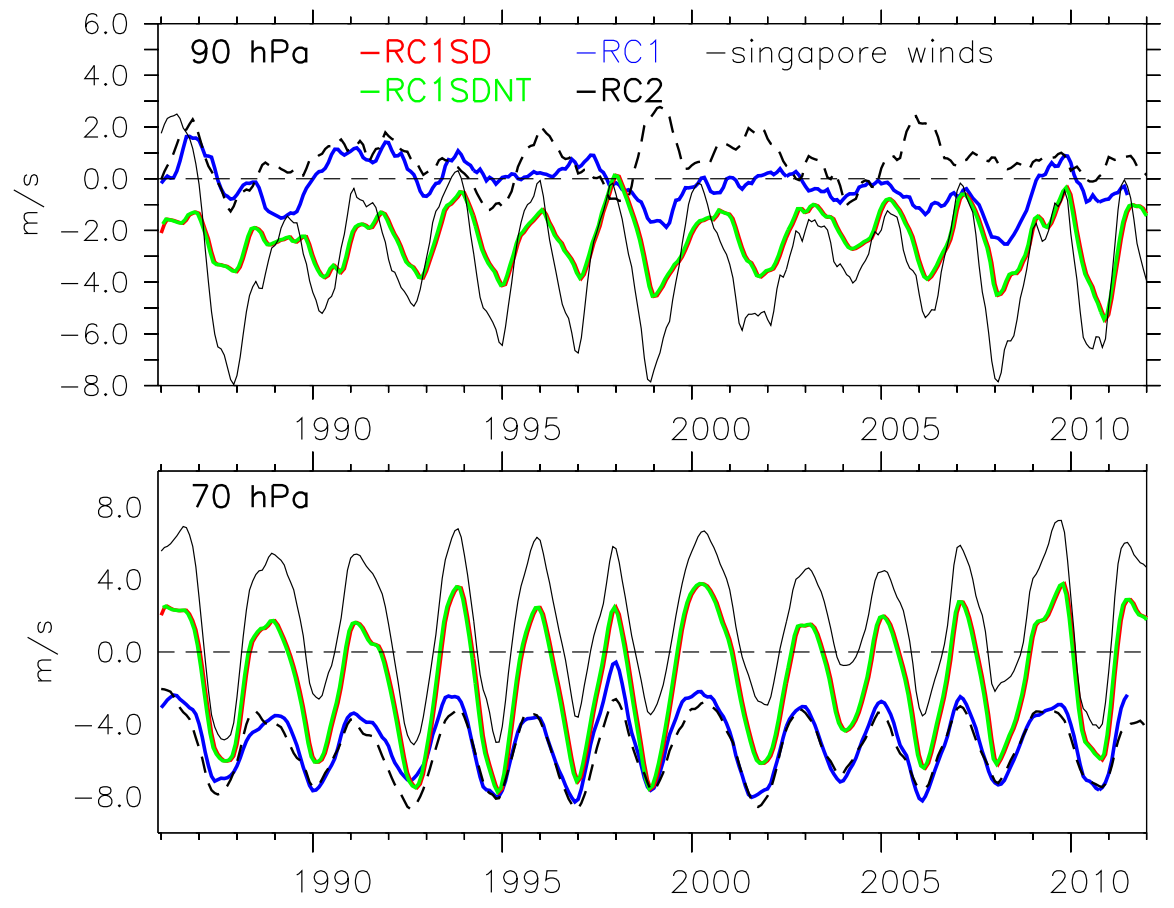

Figure S1: Temporal evolution of the zonal wind component $(\mathrm{m} / \mathrm{s})$ in the tropics (10 S-10 N) at the $90 \mathrm{hPa}$ level (upper figure) and the $70 \mathrm{hPa}$ level (lower figure), (12 month running mean), derived from the RC1SD, RC1SDNT,RC1, and RC2 (dashed line) simulation. The observations (thin black line) are the Singapore radiosonde winds. We selected the time period 1986-2012, because these data had a higher vertical resolution in the tropopause region than in the period before. 

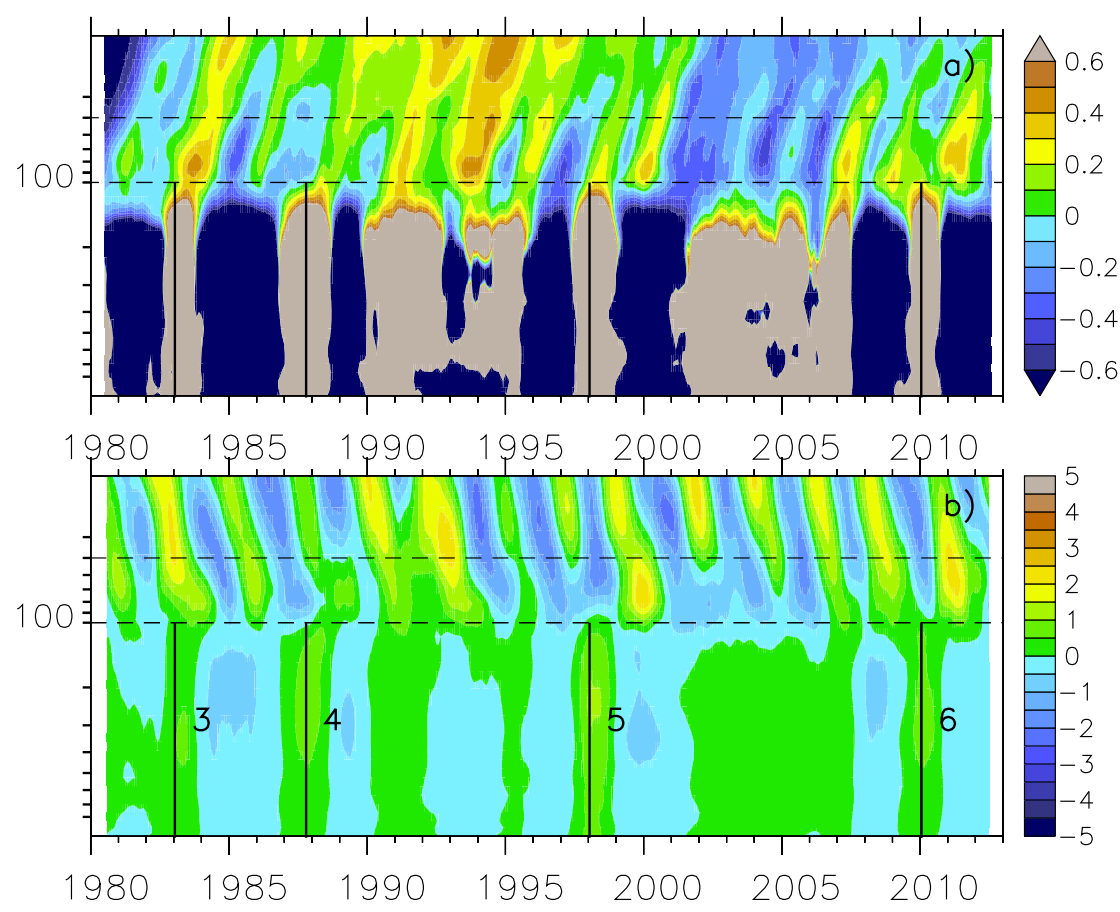

Figure S2: (a) Temporal evolution of moisture anomalies (ppmv). (b) Temporal evolution of temperature anomalies $(\mathrm{K})$ in the tropical region (12 month running mean), derived from the RC1SD simulation. Strong El Niño events are labelled as in Fig. 8 of the manuscript. The altitude range covers the pressure levels from 900 to $30 \mathrm{hPa}$. The dashed lines mark the region between 100 and $50 \mathrm{hPa}$. 


\section{Episode analysis}

The onset of the individual temperature declines at $80 \mathrm{hPa}$ (Fig. S3-S13) is placed at month 0 , so that the periods before the drop and afterwards can be consistently analysed. In the figures, the period of the drop is marked by two vertical lines and the word "drop". We selected the start of the temperature drop (rather than the drop in water vapour), where temperature is at its maximum, for the definition of the corresponding event, because QBO, upwelling and ozone have a direct effect on temperature. Water vapour anomalies follow temperature anomalies directly or with a time lag. All onsets of the temperature drops of RC1SD and RC1 are associated with a minimum in the large-scale upwelling anomaly (Fig. S5), accompanied by a maximum in ozone anomaly (Fig. S6) and for RC1SD only, a west-phase of the QBO (Fig. S7). Accordingly, the minima of the drops show maxima in upwelling, minima in ozone and an east-phase of the QBO (for RC1SD only). The onset of the millennium water vapour drop (Fig. S4, green dashed line) is phase shifted by 3 to 4 months and the 2009/10 water vapour drop about 2 months after the temperature maximum of the corresponding decline (Fig. S3). For the other declines in RC1SD and all declines in $\mathrm{RC} 1$, we find no time lag. $\mathrm{RC} 1$ does not show the transition from west QBO to east QBO phase at the $80 \mathrm{hPa}$ level as a typical feature, because the QBO-phases do not propagate down as far into the TTL as in RC1SD (Fig. S7). Therefore, the contribution of the QBO phase to the drop is less for RC1.

Generally, the correlation between temperature anomaly and QBO anomaly is smaller in RC1 than in RC1SD for the $90 \mathrm{hPa}$ level compared to $70 \mathrm{hPa}$ (Table 2). This points to a different coincidence of upwelling and QBO in RC1, which might partly explain, why the anomalies in temperature and hence water vapour at TTL level are smaller in RC1.

The analysis of small declines of the RC1SD simulation (Fig. S8 - Fig. S12) confirms our results. Small declines are not necessarily accompanied by the changing west to east phase anomaly of the QBO. A clear negative anomaly in upwelling (at the onset in phase 1) only exists for one decline. However, the amplitudes of the upwelling anomalies are smaller than the respective amplitudes for the large declines (Fig. S5). 

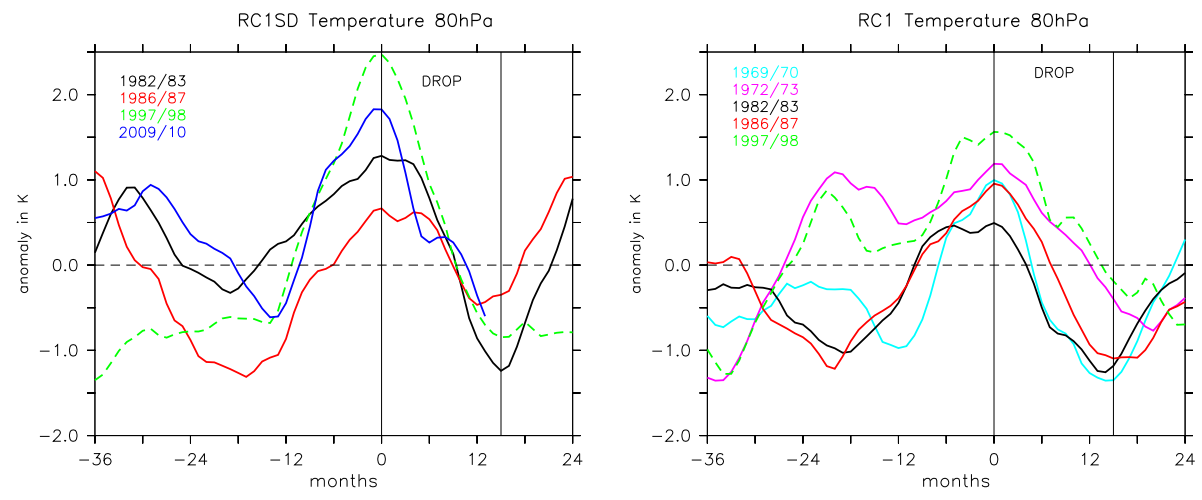

Figure S3: Episode analysis of the zonal mean temperature anomaly at $80 \mathrm{hPa}$, tropical mean $(10 \mathrm{~S}-10 \mathrm{~N})$, de-seasonalized, de-trended, 12-point running mean, related to 4 different El Niño events in the RC1SD (left) and the RC1 (right) simulation. All episodes are referenced to the beginning of the respective temperature drop.
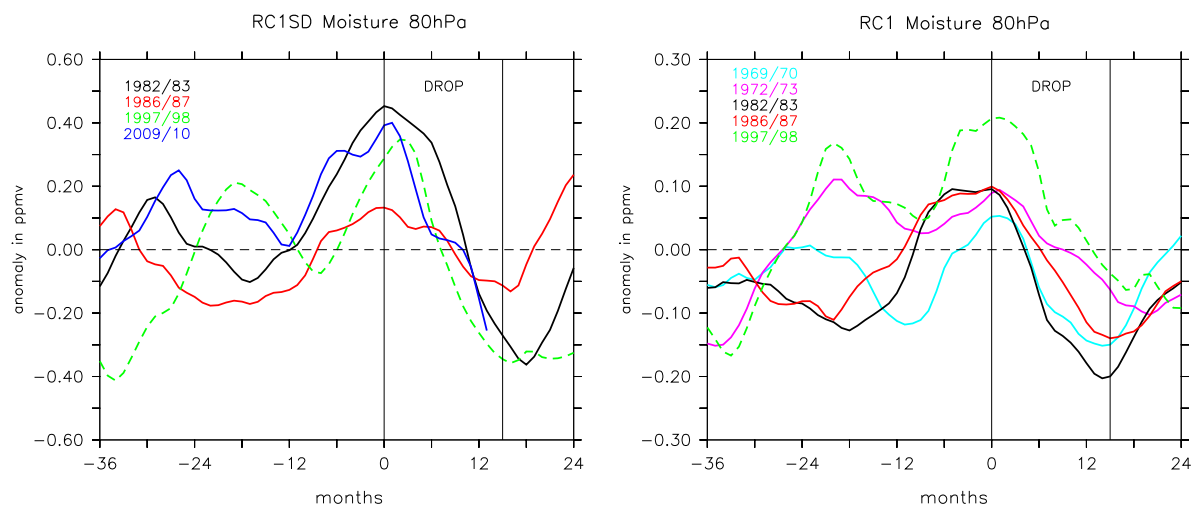

Figure S4: Same as Fig. S3, but for the water vapour anomaly. Note that the vertical axis is smaller in the right figure. 

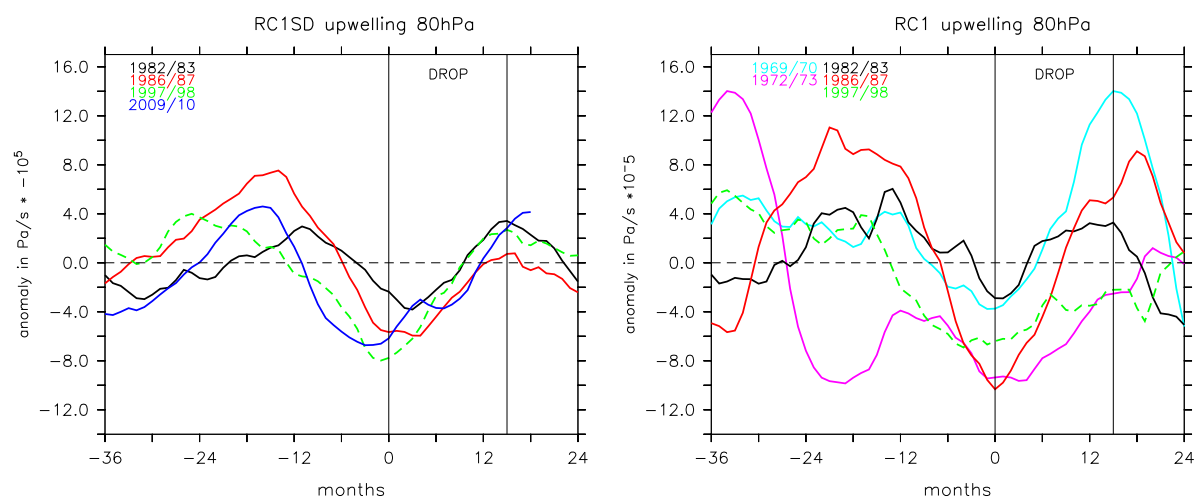

Figure S5: Same as Fig. S3, but for tropical upwelling anomaly.
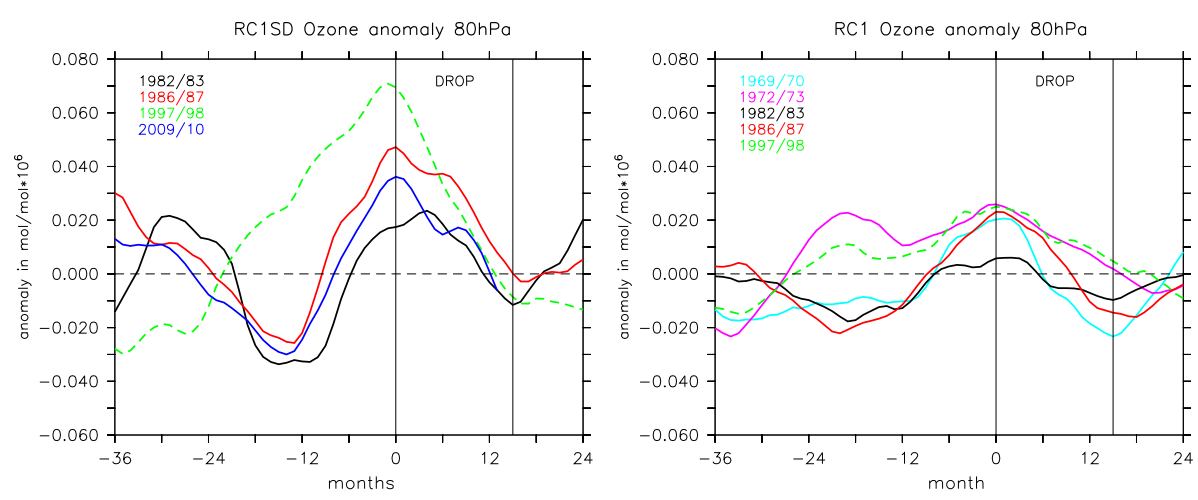

Figure S6: Same as Fig. S3, but for the ozone anomaly.
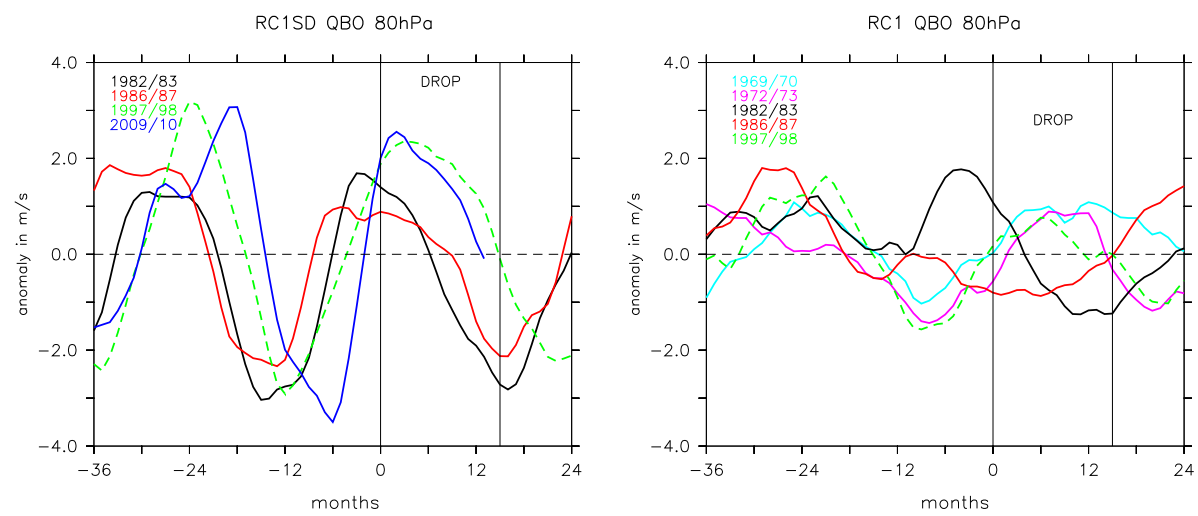

Figure S7: Same as Fig. S3, but for the QBO anomaly. The QBO is represented through the zonal wind anomaly. 


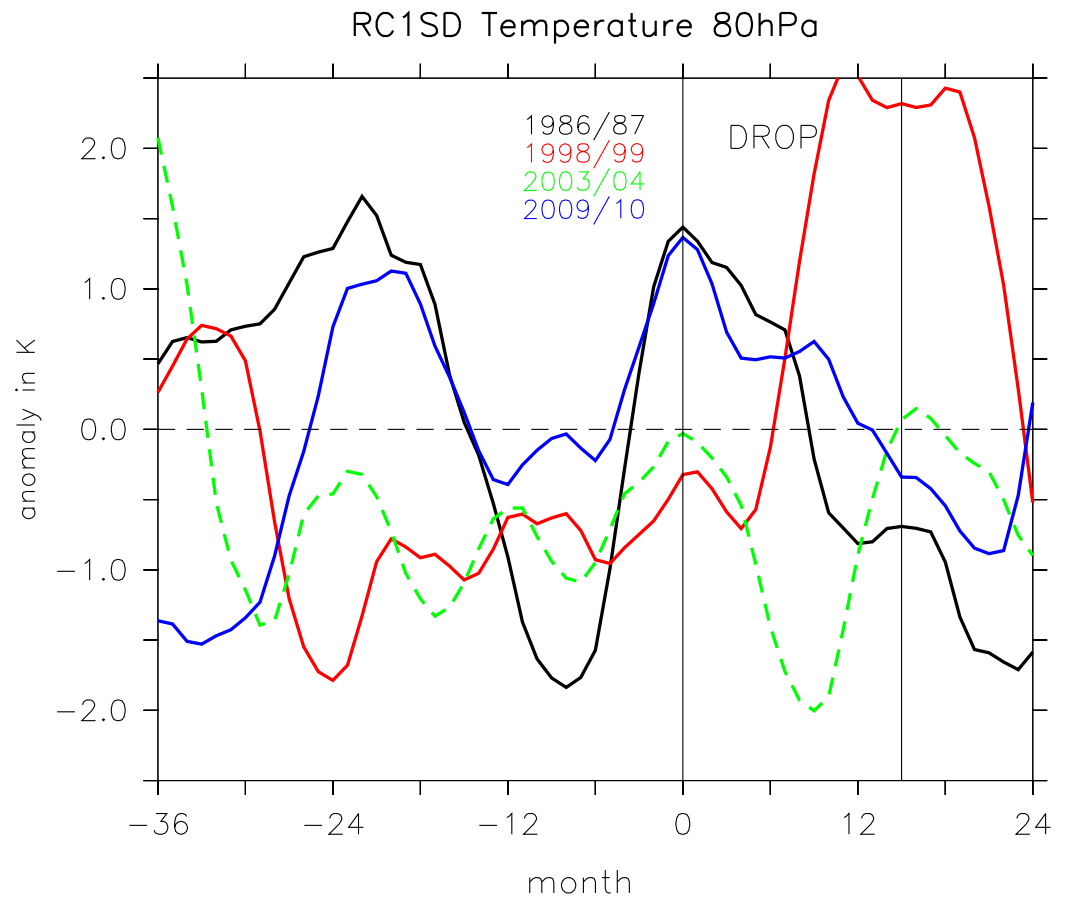

Figure S8: Episode analysis of the zonal mean temperature anomaly at 80 $\mathrm{hPa}$, tropical mean $\left(10^{\circ} \mathrm{S}-10^{\circ} \mathrm{N}\right)$, de-seasonalized, de-trended, 12-point running mean, related to declines WITHOUT preceding El Niño events in the RC1SD simulation. All episodes are referenced to the beginning of the respective temperature decline. Note, the years in the figures are, in contrast to Figs. S3-S7, the years of the water vapour decline and NOT related to a preceding El Niño! 


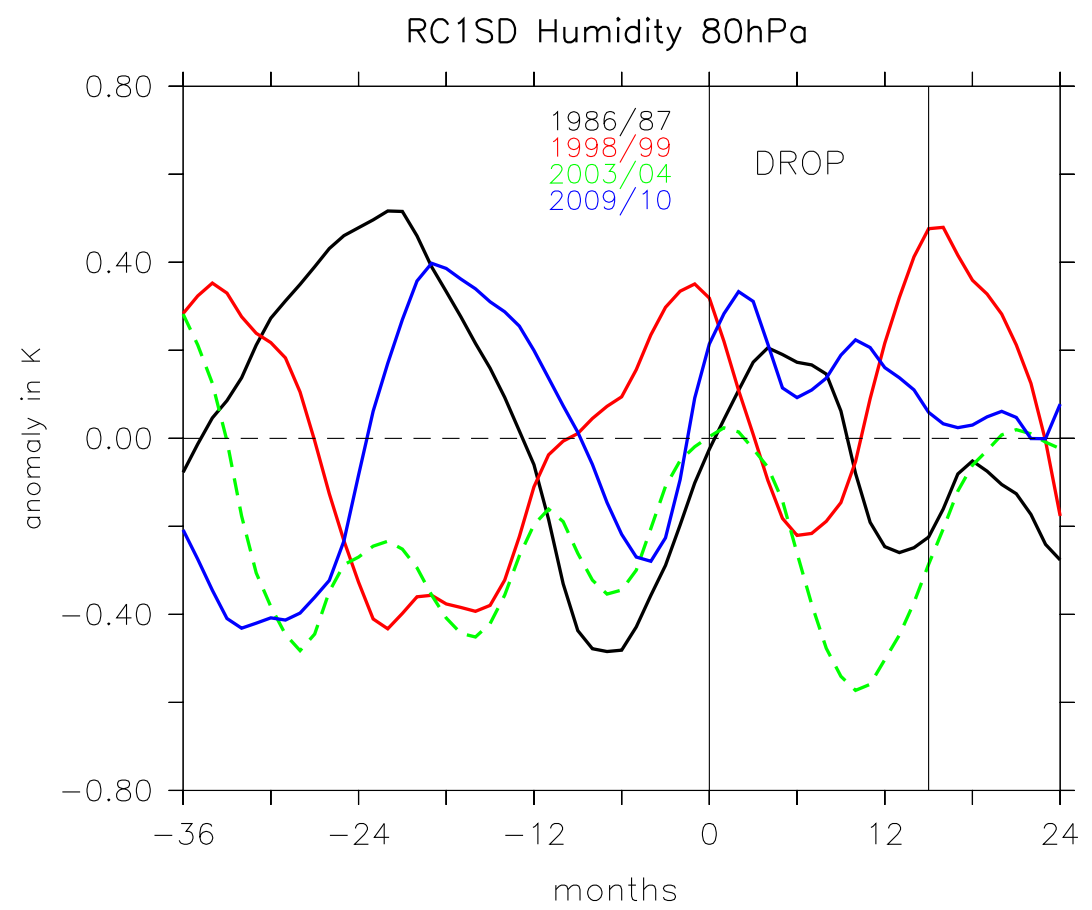

Figure S9: Same as Fig. S8, but for the water vapour anomaly. 


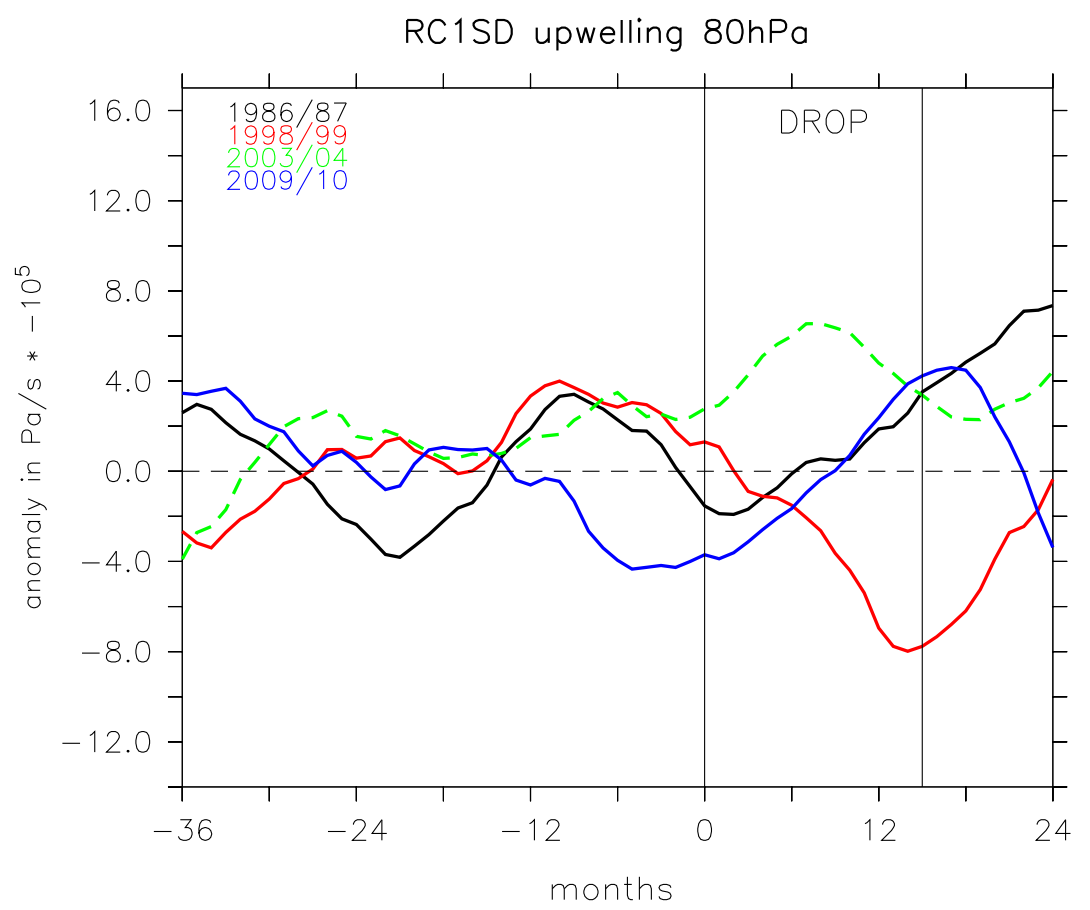

Figure S10: Same as Fig. S8, but for tropical upwelling anomaly. 


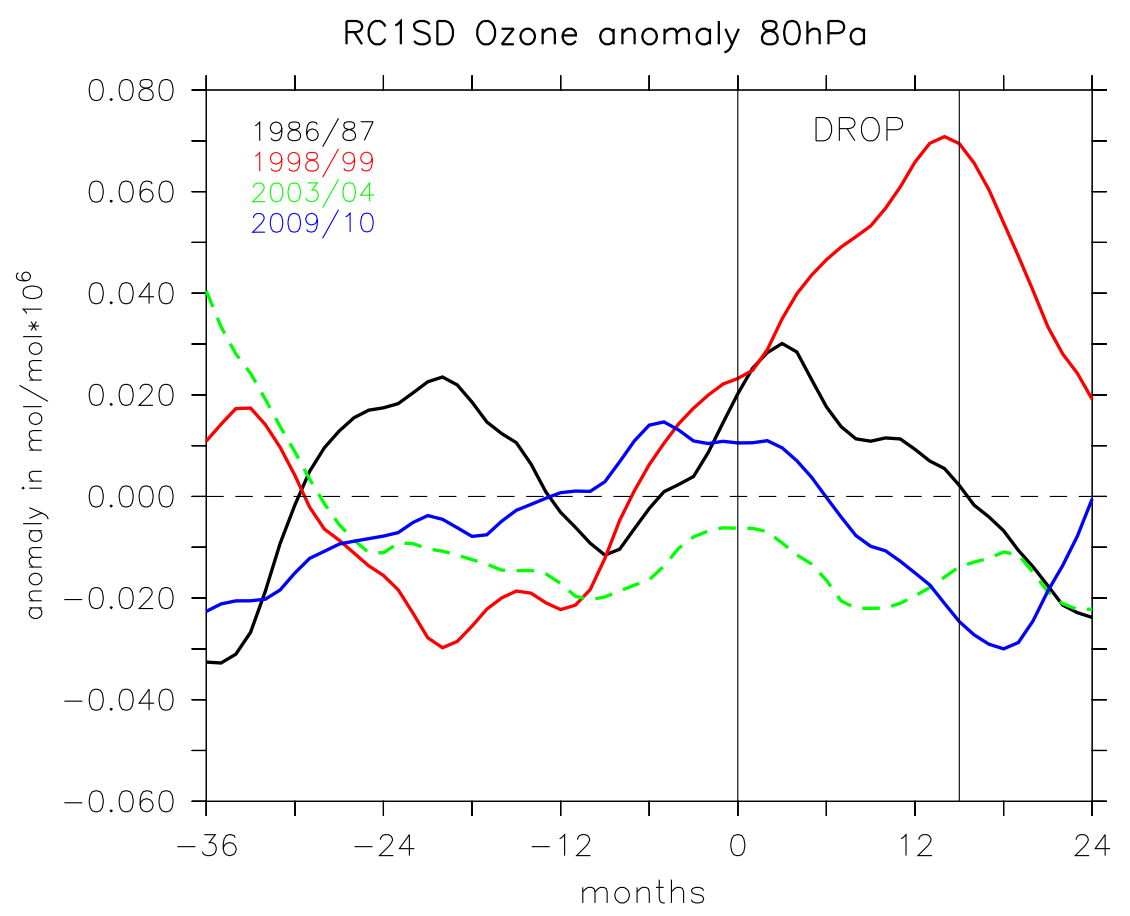

Figure S11: Same as Fig. S8, but for the ozone anomaly. 


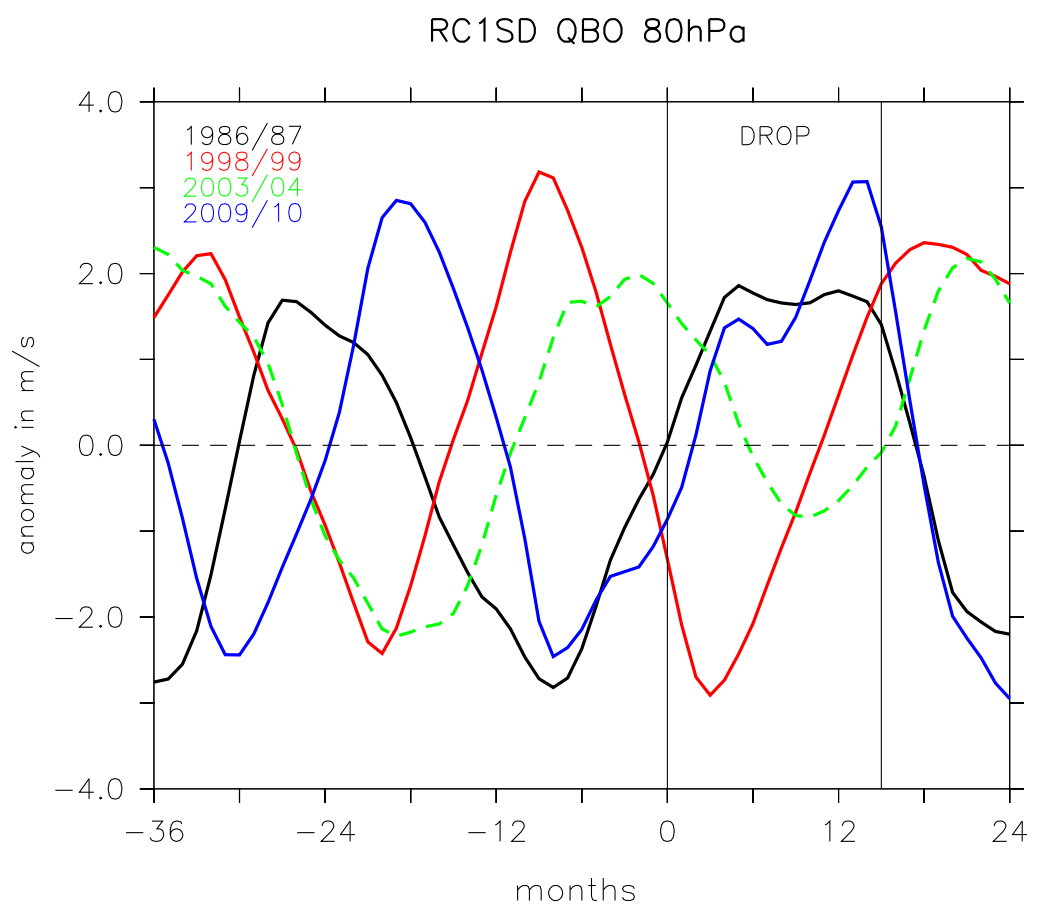

Figure S12: Same as Fig. S8, but for the QBO anomaly. 

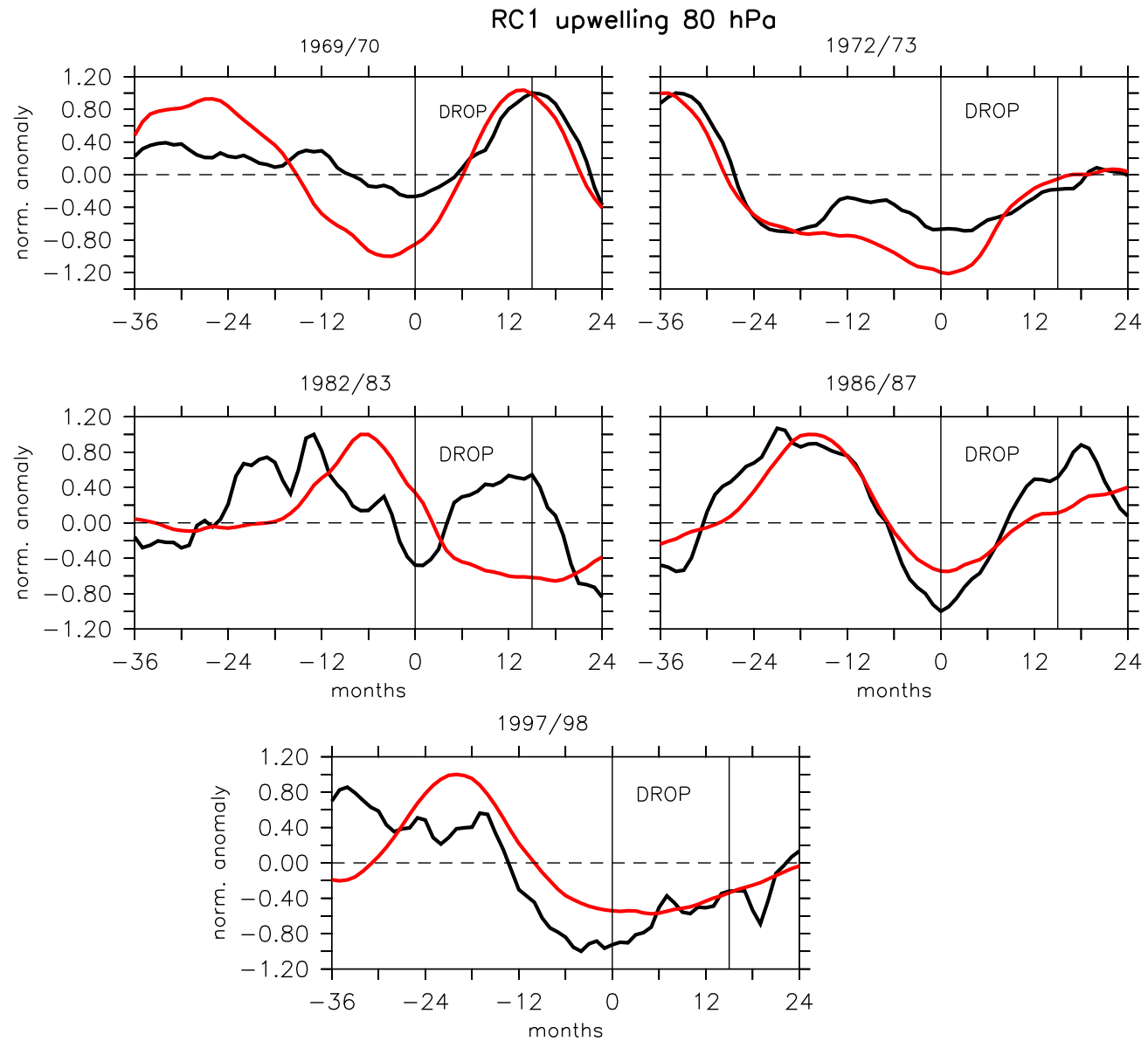

Figure S13: Episode analysis for the normalised upwelling anomaly at $80 \mathrm{hPa}$ (black) for $(10 \mathrm{~N}-10 \mathrm{~S})$ and the max-normalised SST anomaly for the El Niño index 3.4 region (red). The normalised upwelling anomaly is calculated by division of either the maximum or the absolute value of the minimum. For the SSTs it is defined accordingly. Therefore, the results are dimensionless. All episodes are referenced to the beginning of the temperature drop. The drop onsets are accompanied by a negative upwelling anomaly. 